\title{
Taphonomy Methods:
}

Samples were collected for taphonomic analysis by excavating $4820 \mathrm{~cm}$ horizontal x 10 $\mathrm{cm}$ vertical sections of outcrop for available $A$. cervicornis at 3 different locations within the Las Clavallinas outcrop. The 3 sites were chosen to represent the base of the section (oldest deposits), contemporaneous but shallower water deposits across the gully, and the top of the section (youngest deposits). Elevations for all samples are reported relative to a -14.64 m below present (year 2000) benchmark (Greer, 2001). Taphonomy values were assigned based on an adapted taphonomy grade scale of 1 to 5 which factored corallite and fine scale skeletal preservation, dissolution and porosity, angularity or roundness of broken edges or skeletal protrusions, and friability of specimens (Supplemental Fig. DR1). Grade 1 (Pristine) corresponds to corallites clearly preserved, corallite tips intact, small ridges clearly defined on coral surface, and angular, not rounded edges of coral specimens (Supplemental Fig. DR2). Grade 5 (highly degraded) corresponds to high dissolution, void space where corallites should be located, friable or 'crumby' nature of specimen, very well rounded edges and corners of broken specimens.
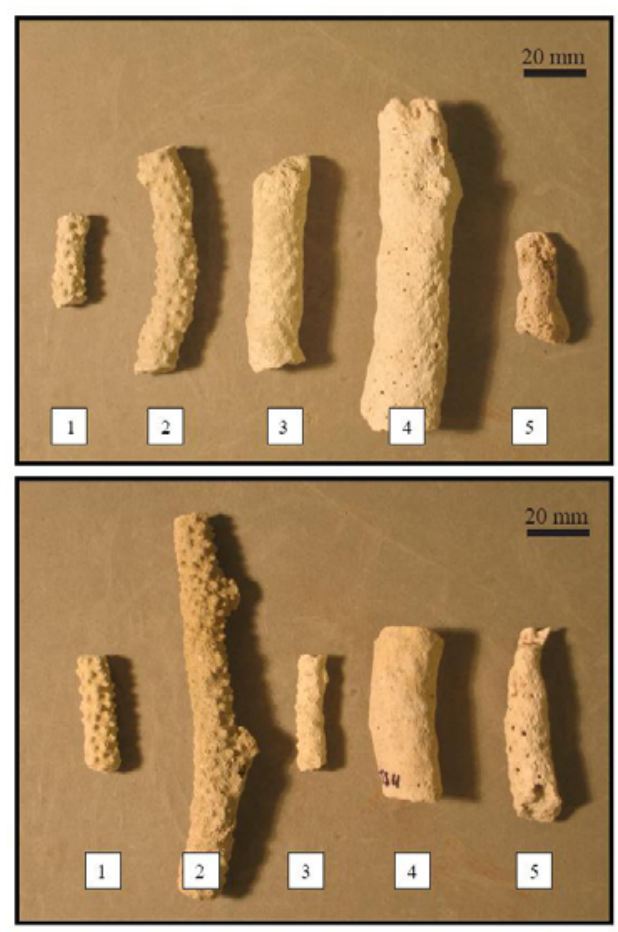

Supplemental Fig. DR1: Numbered taphonomy grades listed below each sample include 1) pristine, 2) slightly weathered, 3) moderately weathered, 4) weathered, and 5) degraded. For a more detailed description of taphonomic grading criteria, see Supplemental Fig. 2). 


\section{Taphonomy Grades}

The taphonomic scale is a measure of how well a particular coral fossil has been preserved. This scale (Fig. 4) is for use with Acropora cervicornis staghorn coral and has been divided into five grades, based on criteria for each taphonomic level: character of corallites, nature of tiny ridges, and roundness of coral edges.

Grade 1 - Pristine condition

- corallites clearly preserved, tips of corallites intact

- tiny ridges clearly defined on surface

- corners of coral are not rounded, breaks are sharp

Grade 2 - Slightly weathered

- tips of corallites have been weathered away

- tiny ridges are not sharply defined

- corners of coral are not rounded, breaks are fairly sharp

Grade 3 - Moderately weathered

- corallites are present as bumps rather than protrusions

- tiny ridges are no longer present on surface

- corners of coral begin to become rounded

Grade 4 - Weathered

- corallites are not present

- surface of coral is very smooth

- corners of coral are rounded

Grade 5 - Degraded

- pockets exist where corallites once were

- surface is degraded, has holes, or is crumbly

- corners are very rounded

Supplemental Figure DR2. Taphonomic grading criteria used in the field.

\section{Taphonomy Results:}

Supplemental Figure DR3 shows mean and standard deviation taphonomy values for all samples analyzed. LC J refers to the 2 meter section at the base, and deepest water section of the fossil reef. LC $\mathrm{J}$ is the location for all data presented in Figure 2 of the manuscript. LC L refers to an adjacent LC site, a contemporaneous but shallower section of reef. LC K refers to the youngest, post-HTM coral section at the top of the LC outcrop. In order to plot all taphonomy data on a time line (for illustrative purposes), some ages were interpolated from available radiocarbon data (interpolated dates are indicated in Supplemental Table 1). As we only obtained one radiocarbon date from LC K, we cannot interpolate relative ages and have plotted taphonomy data on a linear scale for illustrative purposes. 

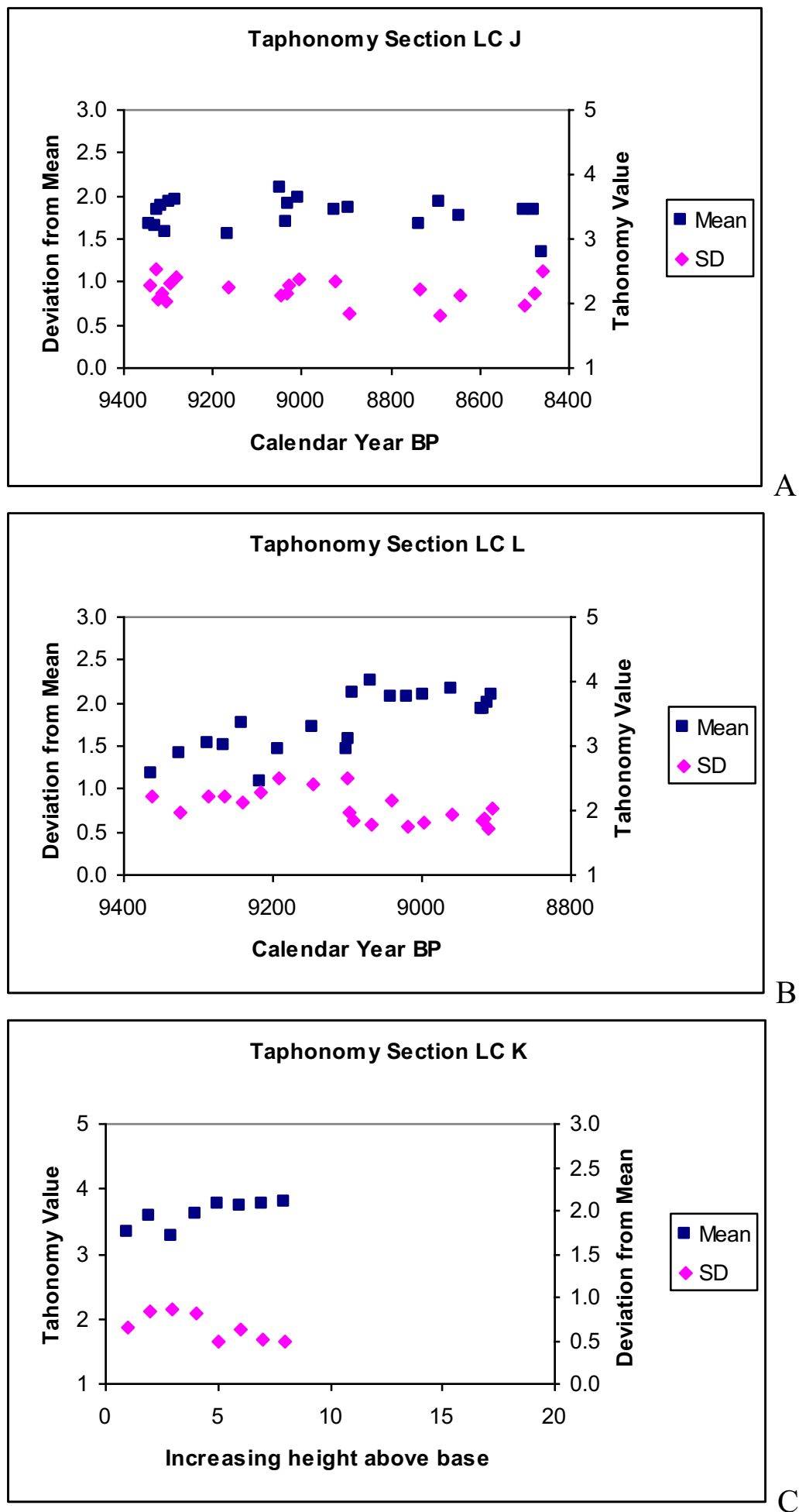

Supplemental Figure DR3: Taphonomy data for each LC site. LC J (A) represents the basal deepest (paleo)water LC site. LC L (B) represents contemporaneous shallow water reef accretion, and LC K (C) represents the shallowest and youngest $A$. cervicornis accumulation. The irregular spacing of data points is a function of age interpolation rather than uneven sampling strategies. 


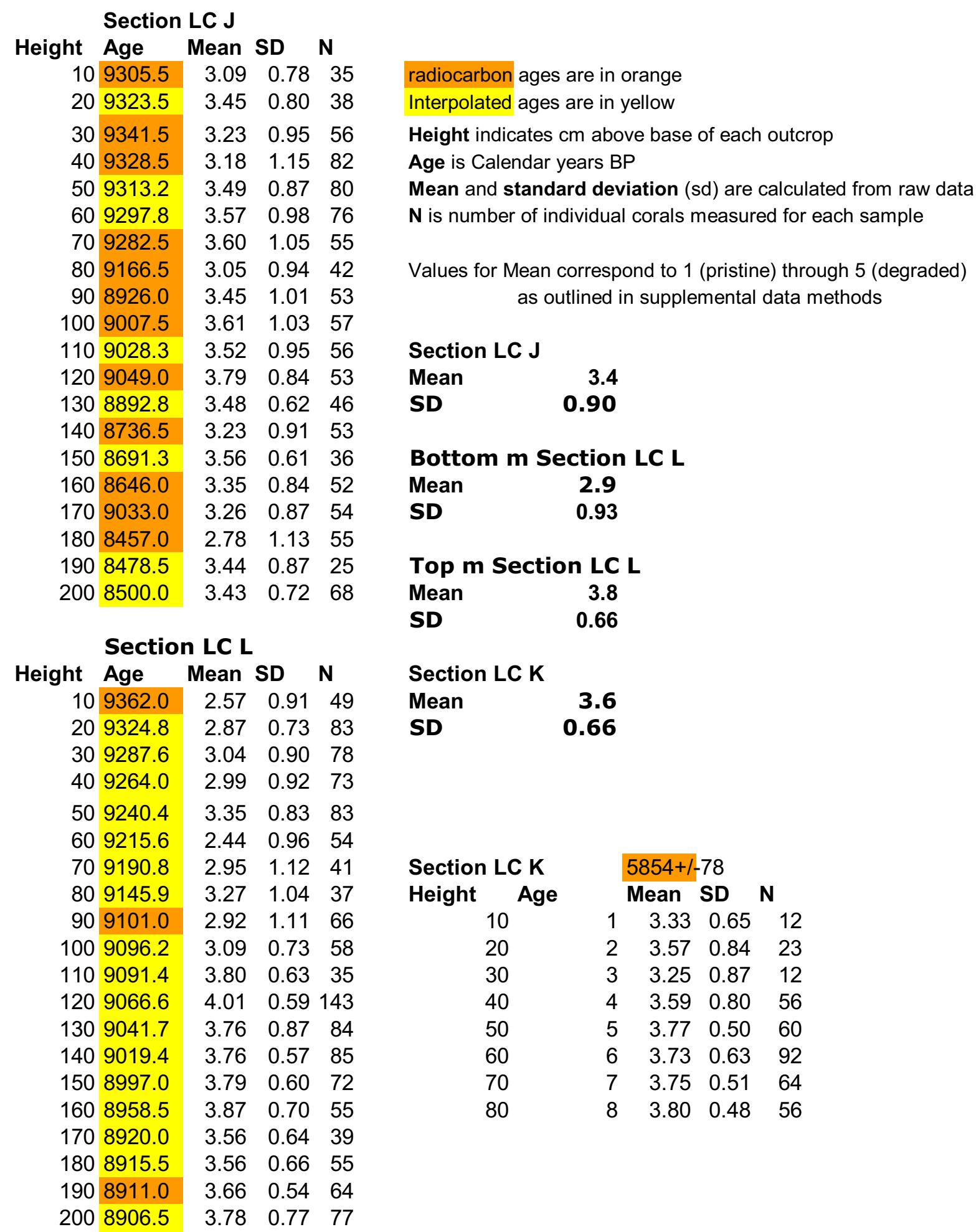

The above age model was used to plot taphonomic data. Some ages are radiocarbon dates and some are interpolated. Please see additional file for complete radiocarbon data for the $\sim 2000$ year LC section. 
Table DR1. High Resolution Age Data

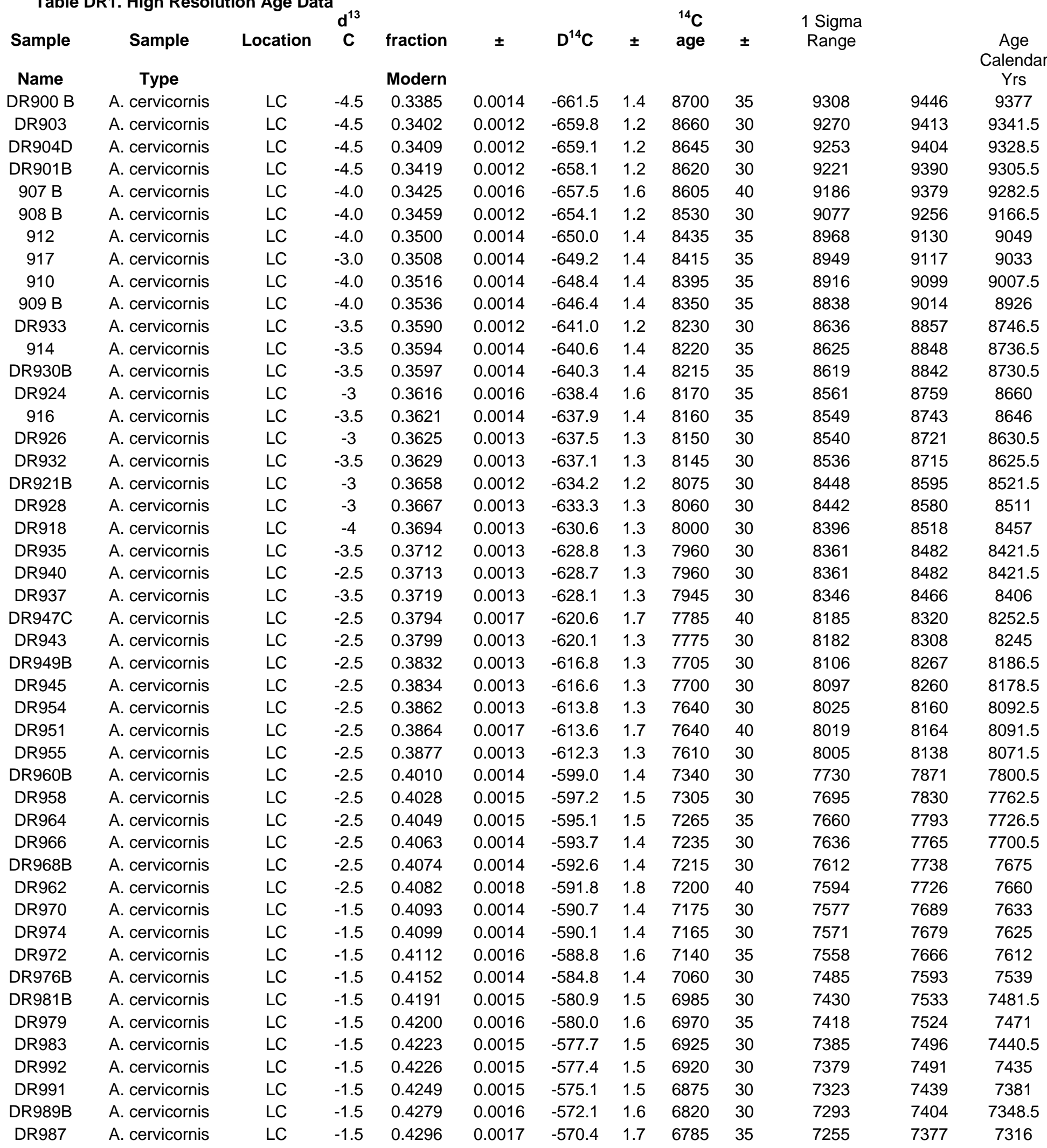


Table DR2. Additional Age and I sotope Data

\begin{tabular}{|c|c|c|c|c|c|}
\hline Sample ID & Speciman Location & Long & Radiocarbon Age & d180 & $\mathbf{N}$ \\
\hline DR A1-3 & A. cervicorni LC & $1830.077 \mathrm{~N} 7132.800 \mathrm{~W}$ & $9362+/-73$ & & \\
\hline DR E1-6 & A. cervicorni LC & $1830.077 \mathrm{~N} 7132.800 \mathrm{~W}$ & $9088.5+/-84$ & & \\
\hline DR J2-6 & A. cervicorni LC & $1830.077 \mathrm{~N} 7132.800 \mathrm{~W}$ & $8861+/-15.5$ & & \\
\hline DR 21-7J & A. cervicorni LC & $1830.077 \mathrm{~N} 7132.800 \mathrm{~W}$ & $8292.5+/-64.5$ & & \\
\hline DR 21-5J & A. cervicorni LC & $1830.077 \mathrm{~N} 7132.800 \mathrm{~W}$ & $7711.5+/-64.5$ & & \\
\hline DR 21-3Jb & A. cervicorni LC & $1830.077 \mathrm{~N} 7132.800 \mathrm{~W}$ & $7328.5+/-57.5$ & & \\
\hline DR KD D3 & A. cervicorni LC & $1830.077 \mathrm{~N} 7132.800 \mathrm{~W}$ & $5854+/-78$ & -2.61 & 150 \\
\hline DR CG B1-5 & A. cervicorni CG & $1832.576 \quad 7147.968$ & $5699+/-80$ & -2.94 & 92 \\
\hline $\mathrm{DR} \mathrm{CH} 1.5$ & A. cervicorni $\mathrm{CH}$ & $1832.020 \mathrm{~N} 7137.202 \mathrm{~W}$ & $5800+/-71$ & & \\
\hline DR CH1.7 1 & A. cervicorni $\mathrm{CH}$ & $1832.020 \mathrm{~N} 7137.202 \mathrm{~W}$ & $5382+/-71$ & & \\
\hline DR LD* & Tellina goulc LC & $1830.077 \mathrm{~N} 7132.800 \mathrm{~W}$ & 8577 & & \\
\hline DR LP* & Codakia orb LC & $1830.077 \mathrm{~N} 7132.800 \mathrm{~W}$ & 8382 & & \\
\hline$D R K G^{*}$ & Arcopsis adi LC & $1830.077 \mathrm{~N} 7132.800 \mathrm{~W}$ & 5608 & & \\
\hline
\end{tabular}

Age is reported in Calyr with 1 sigma value.

*Additional dates obtained from non A. cervicornis material courtesy of A. Martini

d180 values are reported relative to PDB

$\mathrm{N}=$ number of powdered carbonate samples analysed from each individual coral sample

all $\mathrm{d} 180$ values were analyzed by were roasted in vacuo at $200^{\circ} \mathrm{C}$ and analyzed by reaction with phosphoric acid at $70^{\circ} \mathrm{C}$ using a Kiel-III carbonate preparation device directly coupled to a Thermo-Finnigan MAT 252 in the Saskatchewan Isotope Laboratory. 